\title{
Correctable Plasma Lipoprotein Abnormalities in Infants with Choledochal Cysts
}

\author{
GLENN J. WILLIAMS, PETER F. WHITINGTON, STUART W. WEIDMAN, DENNIS D. BLACK, \\ AND SEYMOUR M. SABESIN \\ Departments of Pediatrics and Medicine, The University of Tennessee Center for the Health Sciences, and Le \\ Bonheur Children's Medical Center, Memphis, Tennessee
}

\begin{abstract}
Plasma lipoproteins from two female patients-patient A, 4 wk and patient $B, 19$ months-were examined prior to and at 1 and 5 wk after surgical correction of biliary obstruction due to choledochal cyst. The findings were correlated with standard indices of hepatic function, namely SGPT, GGTP, 5'nucleotidase, serum bile salts, and total and conjugated bilirubin. Prior to surgery in both patients plasma cholesterol, phospholipid, and triglyceride were elevated; cholesterol esters were low; high-density lipoprotein (HDL) cholesterol and apolipoprotein $A-I$, the major protein constituent of $H D L$, were subnormal; most of the plasma lipids were contained in the low-density lipoprotein density region; lipoprotein-X was present. Patient $B$ had had a relatively brief obstruction and suffered little secondary hepatic injury. One week after surgery, plasma lipid concentrations returned to normal; apoliprotein A-I increased in the HDL density region and a concomitant rise in cholesterol esters to near normal, $65 \%$, was observed; plasma lipids were contained predominantly in HDL; hepatic function improved markedly. Patient $\mathbf{A}$ had had intrauterine obstruction and suffered major hepatic injury with cirrhosis. One week after surgery, plasma lipid concentrations, cholesterol esters, low-density lipoprotein lipid predominance, and hepatic function remained essentially unchanged. Five weeks after surgery, the lipoprotein levels and composition and hepatic function were near normal. In conclusion, children with biliary obstruction have lipoprotein abnormalities similar to those seen in adult patients. These alterations are rapidly reversible with surgical relief and may be used as prognostic indicators of outcome. (Pediatr Res 19: 240-247, 1985)
\end{abstract}

\section{Abbreviations}

CH, cholesterol

PL, phospholipid

VLDL, very low-density lipoprotein

apo, apolipoprotein

TG, triglyceride

LpX, lipoprotein-X

UC, unesterified $\mathrm{CH}$

HDL, high-density lipoprotein

LCAT, lecithin/CH acyltransferase

IDL, intermediate density lipoprotein

Received June 26, 1984: accepted September 14, 1984.

Address all correspondence to Peter F. Whitington, M.D., Department of Pediatrics, University of Chicago, 5825 Maryland Avenue, Chicago, IL 60637

This work was supported in part by the following extramural grants: National Institutes of Arthritis, Diabetes, Digestive and Kidney Disease National Research

Service Award (AMO6739-DB); a National Institutes of Health Grant (HL23945SS); a University of Tennessee intramural Grant RO7 3231-93 (P.F.W.).
VHDL, very HDL

SDS, sodium dodecylsulfate

PAGE, polyacrylamide gel electrophoresis

Cholestasis from intra- or extrahepatic disease is often complicated by alterations of plasma lipids, especially when it is severe and persistent $(24,25)$. Characteristically, plasma concentrations of $\mathrm{CH}$ and PL are increased, and the plasma lipoproteins exhibit altered composition and morphology. The electrophoretic mobility of VLDL changes from pre- $\beta$ to $\beta$ probably because of altered apo and lipid composition. The LDL fraction becomes heterogeneous: TG-rich particles and Lp-X, stacked bilamellar discoidal particles with an outer lipid bilayer composed predominantly of a 1:1 molar mixture of UC and PL and an aqueous interior containing albumin and apo C-III, appear $(10,27,28)$. HDL concentration is reduced, and abnormal discoidal HDL particles are seen. These disturbances presumably result from altered hepatic lipid metabolism, albeit the precise defects are not known.

Correctable cholestatic liver disease presents an interesting human model for studying the function of the liver in lipid metabolism: the abnormalities can be analyzed and the course of recovery studied to determine the liver's role. There have been few such studies in adults and none in children. Arnesjo et al. (3) studied the HDL abnormalities in biliary obstruction in adults by zonal ultracentrifugation and found they were reversed within about $3 \mathrm{wk}$ of surgery. Other workers have found a rapid decrease in plasma PL and UC with a simultaneous increase in EC after correction of biliary obstruction (32). Similar studies in young children are lacking because reversible extrahepatic biliary obstruction in infants is rare. Herein we detail the lipoprotein abnormalities of two pediatric patients with choledochal cysts and their rapid reversal after surgical correction.

\section{SUBJECTS AND METHODS}

Case reports. Patient A was a white female admitted at 3 wk of age for evaluation of cholestasis. The clinical and pathological features of this case are detailed elsewhere (18). Jaundice had appeared on the 1st day of life, and by 1 wk the bilirubin was $11 / 9 \mathrm{mg} / 100 \mathrm{ml}$. Dark urine and acholic stools had been noted by the parents. The birth weight was $2585 \mathrm{~g}$. The physical exam revealed a small, icteric infant with a weight of $2.95 \mathrm{~kg}$. The liver was firm and enlarged to $6 \mathrm{~cm}$ below the right costal margin, and the spleen was $2 \mathrm{~cm}$ below the left costal margin. No abdominal mass was palpable.

The clinical laboratory data (see Table 1) documented cholestasis. Common infectious and metabolic etiologies were excluded, a percutaneous liver biopsy demonstrated biliary cirrho- 
Table 1. Clinical laboratory data

\begin{tabular}{|c|c|c|c|c|c|c|}
\hline & $\begin{array}{c}\text { SGOT } \\
\text { (U/liter) }\end{array}$ & $\begin{array}{c}\text { SGPT } \\
\text { (U/liter) }\end{array}$ & $\begin{array}{c}\text { Total bilirubin } \\
(\mathrm{mg} / \mathrm{dl})\end{array}$ & $\begin{array}{l}\text { Direct bilirubin } \\
(\mathrm{mg} / \mathrm{dl})\end{array}$ & $\begin{array}{c}\text { GGTP } \\
\text { (U/liter) }\end{array}$ & $\begin{array}{c}\text { 5'Nucleotidase } \\
\text { (U/liter) }\end{array}$ \\
\hline Normal & & $0-54$ & & & $0-103$ & $0-17$ \\
\hline \multicolumn{7}{|l|}{ Patient A } \\
\hline Preop & 217 & 77 & 9.0 & 3.4 & 212 & 79 \\
\hline Postop 1 wk & 121 & 59 & 9.2 & 2.5 & 228 & 40 \\
\hline Postop 5 wk & 99 & 79 & 0.8 & 0.25 & 182 & 50 \\
\hline \multicolumn{7}{|l|}{ Patient B } \\
\hline Preop & 254 & 145 & 10.4 & 8.4 & 1326 & 440 \\
\hline Postop $1 \mathrm{wk}$ & 58 & 22 & 1.0 & 0.8 & 110 & 73 \\
\hline Postop 5 wk & 38 & 15 & 1.0 & 0.1 & 5 & 7 \\
\hline
\end{tabular}

sis and suggested the presence of extrahepatic biliary obstruction, and abdominal ultrasound demonstrated a cystic lucency in the area of the porta hepatis. A type I-A choledochal cyst (2) was documented and partially resected at surgery, and a Roux-en-Y cyst-jejunostomy was established to provide bile drainage. The patient has done well postoperatively. She experienced one episode of cholangitis 2 months after surgery, but responded well to antibiotic therapy. A percutaneous liver biopsy performed at 11 months demonstrated inactive biliary cirrhosis, and a HIDA scan showed no residual biliary obstruction. The postoperative clinical laboratory data are given in Table 1 . Growth and development are normal at 18 months of age.

Patient B was a 19 month old white female admitted for evaluation of jaundice. She had been in good health until $1 \mathrm{wk}$ prior to admission when she developed icteric sclerae and skin, light-colored stools, and dark urine. These symptoms persisted and were not accompanied by any other complaints. The physical exam revealed an icteric, well-nourished child with the liver 4 $\mathrm{cm}$ below the RCM. The gallbladder was palpable.

The clinical laboratory data, given in Table 1, suggested extrahepatic biliary obstruction as the cause for cholestasis. An abdominal ultrasound revealed a large cystic structure in the porta hepatis. An intraoperative cholangiogram showed a normal size gallbladder, good filling of the cystic duct, a type I choledochal cyst proximal to the cystic duct/hepatic duct junction, and slightly dilated intrahepatic biliary radicles. The cyst was resected, and a Roux-en-Y choledochojejunostomy was constructed. The liver biopsy showed biliary cirrhosis. The patient did well postoperatively with rapidly clearing icterus. Follow-up data are given in Table 1. This patient has continued to do well, and a liver biopsy performed at 23 months of age showed normal liver with minimal residual portal fibrosis.

Collection of samples and sample handling. All blood samples for lipoprotein studies were collected in the fasting state in EDTA $(1.5 \mathrm{mg} / \mathrm{ml})$ tubes to which $5,5^{\prime}$-dithionitrobenzoic acid $(1 \mathrm{mM})$ was added to inhibit LCAT activity. Also, a preservative solution was added to each sample to yield a final concentration of $0.02 \%$ azide, $0.0001 \%$ chloramphenicol, and $0.0005 \%$ gentamicin. The plasma lipoproteins were separated as follows. The $\mathrm{d}<1.006 \mathrm{~g} /$ $\mathrm{ml}$ lipoproteins were isolated by centrifugation for $17 \mathrm{~h}$ in an SW 50.1 rotor $\left(2 \times 10^{6} \mathrm{~g}\right.$-min $)$ in a Beckman ultracentrifuge (Beckman Instruments, Inc., Palo Alto, CA), and the $\mathrm{d}>1.006$ $\mathrm{g} / \mathrm{ml}$ fraction was separated in a $10 \mathrm{ml}$ exponential salt plus sucrose gradient extending from $\mathrm{d}=1.01$ to $1.4 \mathrm{~g} / \mathrm{ml}$, which has been described and validated previously $(31,33)$. IDL $(\mathrm{d}=1.006$ to $1.019 \mathrm{~g} / \mathrm{ml}), \operatorname{LDL}(\mathrm{d}=1.019$ to $1.063 \mathrm{~g} / \mathrm{ml}), \mathrm{HDL}(\mathrm{d}=1.063$ to $1.21 \mathrm{~g} / \mathrm{ml})$, and very high density lipoprotein $(\mathrm{d}>1.21 \mathrm{~g} / \mathrm{ml})$ float in fractions $1,2-8,9-17$, and $18-20$, respectively. HDL was further divided into "light" (fractions 9-13) and "heavy" (fractions 14-17) subspecies, corresponding approximately to $\mathrm{HDL}_{2}$ and $\mathrm{HDL}_{3}$. TG, PL, CH, and UC were determined in whole plasma, VLDL, and the $\mathrm{d}>1.006 \mathrm{~g} / \mathrm{ml}$ lipoprotein fractions. Fractions 9-20 and whole plasma were analyzed for apo A-I.
Analytical techniques. Total and esterified $\mathrm{CH}$ were determined by gas chromatographic analysis of extracts of saponified and nonsaponified samples containing a known amount of $\beta$ sitosterol as an internal reference (4). Plasma and lipoprotein phospholipids were determined by extraction of samples by sequential addition of 50 volumes of methanol and 50 volumes of chloroform. Extracts were dried under nitrogen, digested with 7\% perchloric acid and phosphorus determined by the method of Rouser et al. (22). Phosphorus values were converted to phospholipid values using a factor of 25 .

Proteins were determined by a modified Lowry technique (15) using crystalline bovine albumin standards. Density gradient apoproteins were analyzed by the SDS-PAGE method of Laemmli (13); separating gels were a $10-20 \%$ polyacrylamide gradient. Gels were stained with $0.05 \%$ Coomassie brilliant blue and destained in the solutions of Weber and Osborn (30).

Apo A-I was determined by the immunoelectrophoresis (rocket) method of Laurell (14) using antibodies prepared in rabbits $(7,8)$. The assay was linear in the range of 30-325 $\mathrm{ng}$ of A-I purified by a preparative SDS polyacrylamide gel electrophoresis method modified from Weber and Osborn (30). All sample dilutions were made in $0.024 \mathrm{M}$ barbital buffer ( $\mathrm{pH}$ 8.6). Preand postoperative samples for a subject were always run on the same immunoassay plate. The within and between assay coefficients of variation were 5 and $7 \%$, respectively.

Electron microscopy. Samples for electron microscopy were exhaustively dialyzed against deionized water containing $1 \mathrm{mM}$ EDTA and $0.02 \%$ sodium azide at $\mathrm{pH}$ 7.6. Lipoproteins were negatively stained for electron microscopy with $2 \%$ phosphotungstate solutions $(\mathrm{pH}=5.9)$. To insure uniformity in morphological analysis of density gradient fractions, lipoproteins were floated on Formvar-coated grids from equal fraction volumes for $3 \mathrm{~s}$. Negative staining was then carried out for $2 \mathrm{~min}$ in an identical manner for all gradient fractions. Gradient fractions 5 (LDL), 8 (Lp-X and heavier LDL), and 12 (HDL) were chosen for study.

Reference values. Table 2 presents lipoprotein lipid and apo A-I values determined in our laboratory on pooled plasma from normolipidemic adults, normal full term infants, and a normal 9-month-old infant. The data are presented for comparison with patient data although comparison of the pre- with the postoperative values are more instructive. We have measured apo A-I in only one control infant. For comparison, Poley et al. (20) give a value of $107.8 \pm 36.5$ (SD) $\mathrm{mg} / \mathrm{dl}$ for four control infants, and the range for normal adult values in our laboratory is $90-150$ $\mathrm{mg} / \mathrm{dl}$.

\section{RESULTS}

Biochemical studies of liver function. Table 1 shows results of biochemical evaluation of liver function of the patients before surgery and 1 and $5 \mathrm{wk}$ after surgery. Both patients had a rapid decline in direct bilirubin with patient $A$ returning to normal by $5 \mathrm{wk}$ and patient $B$ by $1 \mathrm{wk}$ after surgery. The serum transami- 
Table 2. Laboratory normals: lipoprotein lipid and apo A-I concentrations

\begin{tabular}{|c|c|c|c|c|c|}
\hline & $\mathrm{UC}^{*}$ & $\mathrm{EC}^{*}$ & $\mathrm{TG}^{*}$ & PL* & Apo A-I* \\
\hline \multicolumn{6}{|l|}{ Adult $\uparrow$} \\
\hline Whole plasma & 48 & 126 & 78 & 250 & 100 \\
\hline $\mathrm{d}>1.006 \mathrm{~g} / \mathrm{ml}$ & 39 & 128 & 36 & 224 & 103 \\
\hline \multicolumn{6}{|l|}{ 8-day infant: } \\
\hline Whole plasma & $20(13-27)$ & $33(16-49)$ & $91(60-120)$ & $184(133-216)$ & \\
\hline $\mathrm{d}>1.006 \mathrm{~g} / \mathrm{ml}$ & $15(12-20)$ & $29(15-45)$ & $40(36-47)$ & $140(105-174)$ & \\
\hline \multicolumn{6}{|l|}{ 9-mo infant $\$$} \\
\hline Whole plasma & 24 & 56 & 58 & 176 & 74 \\
\hline $\mathrm{d}>1.006 \mathrm{~g} / \mathrm{ml}$ & 21 & 54 & 50 & 154 & 75 \\
\hline
\end{tabular}

* All concentrations are $\mathrm{mg} / \mathrm{dl}$, rounded to the nearest integer for clarity.

$\dagger$ Normolipidemic adults $(n=12)$, pooled samples.

$\ddagger$ AGA full-term infants $(n=4) ; \bar{x}$ (range).

$\S$ Otherwise healthy infant evaluated for gastroesophageal reflux.

Table 3. Lipoprotein lipid and apo A-I parameters of the patients

\begin{tabular}{|c|c|c|c|c|c|c|c|c|c|c|c|c|c|c|c|}
\hline & \multicolumn{3}{|c|}{$\mathrm{UC}^{*}$} & \multicolumn{3}{|c|}{$\mathrm{EC}$} & \multicolumn{3}{|c|}{$\mathrm{TG}$} & \multicolumn{3}{|c|}{ PL } & \multicolumn{3}{|c|}{ Apo A-I } \\
\hline & $0 \dagger$ & $1 \ddagger$ & $5 \ddagger$ & 0 & 1 & 5 & 0 & 1 & 5 & 0 & 1 & 5 & 0 & 1 & 5 \\
\hline \multicolumn{16}{|l|}{ Patient A } \\
\hline Plasma & 198 & 165 & 54 & 98 & 100 & 95 & 299 & 159 & 75 & 700 & 437 & 268 & 52 & 67 & 140 \\
\hline $\begin{array}{r}\mathrm{d}>1.006 \\
\text { fraction }\end{array}$ & 186 & 132 & 45 & 91 & 82 & 91 & 187 & 124 & 47 & 603 & 373 & 228 & 51 & 65 & 130 \\
\hline \multicolumn{16}{|l|}{ Patient B } \\
\hline Plasma & 199 & 55 & 32 & 65 & 104 & 75 & 82 & 186 & 173 & 455 & 276 & 225 & 70 & 140 & 114 \\
\hline $\begin{array}{r}\mathrm{d}>1.006 \\
\text { fraction }\end{array}$ & 175 & 27 & 16 & 40 & 85 & 59 & 60 & 74 & 63 & 443 & 198 & 163 & 62 & 130 & 108 \\
\hline
\end{tabular}

* All concentrations are $\mathrm{mg} / \mathrm{dl}$, rounded to the nearest integer for clarity.

$\dagger$ Preoperative.

$\$$ Postoperative wk.

nases were initially only moderately elevated. They returned to normal by 5 wk in patient $B$, but patient A's values remained elevated, probably because of the more prolonged intrauterine obstruction. Similarly, the serum GGTP and 5'-nucleotidase declined to normal values by $5 \mathrm{wk}$ in patient $\mathrm{B}$ but remained elevated above normal in patient A. Liver histology further supported the more severe hepatic injury sustained by patient $A$ (18).

Preoperative plasma and lipoprotein parameters. Before surgical relief of extrahepatic obstructions, both patients exhibited extensive derangement of their plasma lipoproteins. As illustrated in Table 3, plsma UC and PL concentrations were increased while apo A-I was decreased. Patient A was also hypertriglyceridemic.

Most of the plasma lipids were in the $\mathrm{d}>1.006 \mathrm{~g} / \mathrm{ml}$ fraction (LDL + HDL). The results of the subfractionation of this fraction by density gradient ultracentrifugation are shown in Figures $1 \mathrm{~A}$ and $2 A$. These profiles differ from those of normolipidemic individuals in the following respects: 1) UC is the predominant form of $\mathrm{CH}$ throughout the gradient; 2) most of the PL is found in fractions $1-13 ; 3)$ in fraction 7 and $8(\mathrm{~d}=1.049-1.064 \mathrm{~g} / \mathrm{ml})$ there was a $2: 1$ mass or $1: 1$ molar ratio of PL to UC, suggesting the presence of $\mathrm{Lp}-\mathrm{X}$; 4) there was very little cholesterol in the "heavy" HDL region of the gradient (fractions 14-20); and 5) the total concentration of apo A-I contained in the HDL region of the gradient (fractions 9-20) was low.

The apoproteins of fractions $1-15$ as qualitatively determined by SDS-PAGE in the preoperative sample of patient $\mathrm{B}$ are shown in Figure $3 A$. Patient A's data are not shown but are similar. Such gels from normal fasting individuals contain only apo $B$ in fractions 1-8 (IDL, LDL) and apo A-I, A-II, E, and C in fractions 9-15 (HDL). The gels of the patients differ from those of normals in: 1) the additional presence of apos E, A-I, and C in the LDL density region, 2) in the case of patient $A$, a second apo $E$ peak in fractions 8 and 9 , and 3 ) reduced apo A-I, A-II, and C in the HDL region (fractions 9-15).

Figure 4 demonstrates the morphological abnormalities of lipoproteins in the LDL (gradient fraction 5; Fig. $4 A$ ), Lp-X and heavier LDL (fraction 8; Fig. 4B), and HDL (fraction 12; Fig. $4 C$ ) density regions of plasma from patient $\mathrm{A}$. Whereas a control infant and normal adults exhibit particles of a uniform size and shape in the LDL region (data not shown), patient $A$ had a heterogeneous population of particles with many larger than normal. In fraction 8, the typical stacked discs of Lp-X were evident, and in fraction 12 , various abnormal HDL shapes, including stacked discoidal particles and larger, spherical forms, were seen. Patient B had similar abnormalities (data not shown).

Postoperative recovery in plasma and lipoprotein parameters. Five weeks after surgery, plasma UC and PL levels had decreased considerably (Table 3). The fraction of cholesterol which was esterified was normal in patient B, but patient A's was $64 \%$, still slightly subnormal. Plasma apo A-I and TG levels were normal. Patient B's recovery was much faster than that of patient A, with much improvement occurring by $1 \mathrm{wk}$. The difference in response after surgery probably reflects the difference in severity of their liver injury.

The lipid parameters seen in the $\mathrm{d}>1.006 \mathrm{~g} / \mathrm{ml}$ fraction after surgery are illustrated in Figures $1 B$ and $2 B$. To obtain a clearer picture of the changes from the preoperative state, Figures $1 C$ and $2 C$ were derived by subtraction of pre- from postoperative values. Positive deviations are observed when values increased after surgery and vice versa for negative deviations. The changes observed were decreases of PL and UC in the LDL density region (fractions 2-8), corresponding to decreases in abnormal LDL 


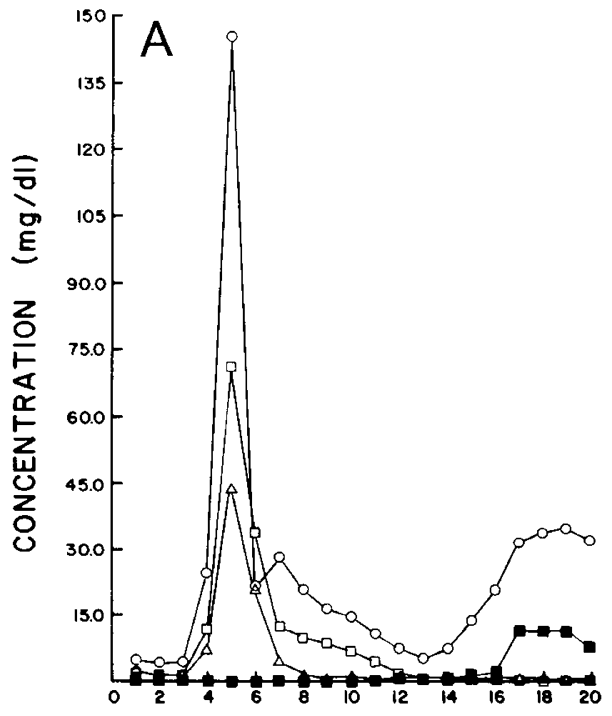

DENSITY GRADIENT FRACTION NO.

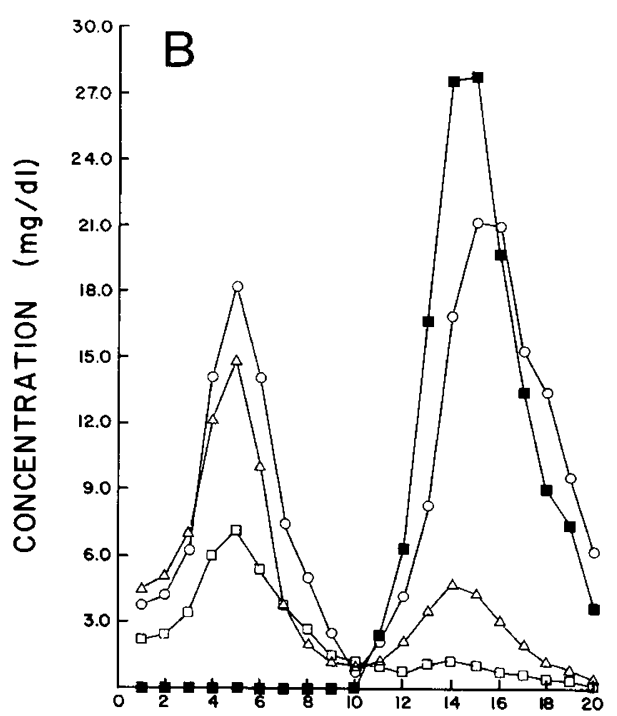

DENSITY GRADIENT FRACTION NO.
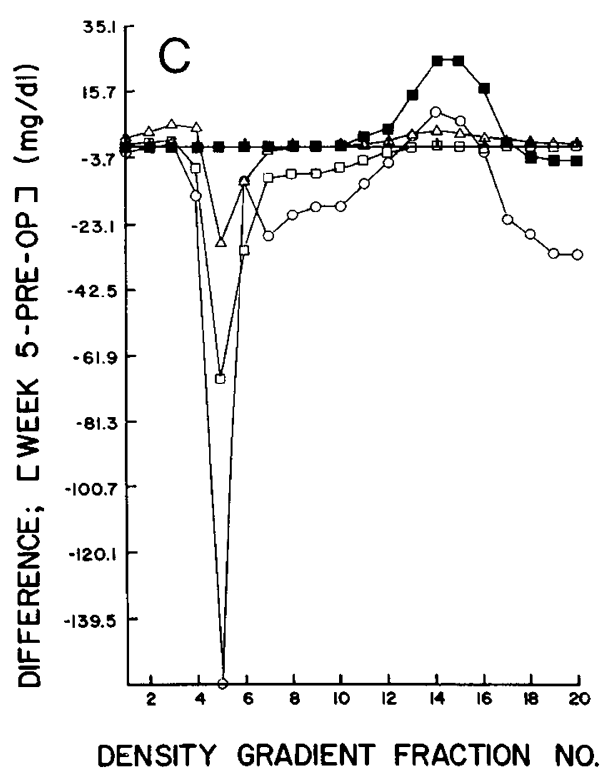

Fig. 1. Density gradient profiles of plasma $\mathrm{d}>1.006 \mathrm{~g} / \mathrm{ml}$ lipoproteins from patient A: $A$, preoperative; $B, 5$ wk postoperative; $C$, difference plot, postoperative minus preoperative values. $(\mathrm{O}, \mathrm{PL} ; \square, \mathrm{UC} ; \triangle, \mathrm{EC}$; apo A-I.)

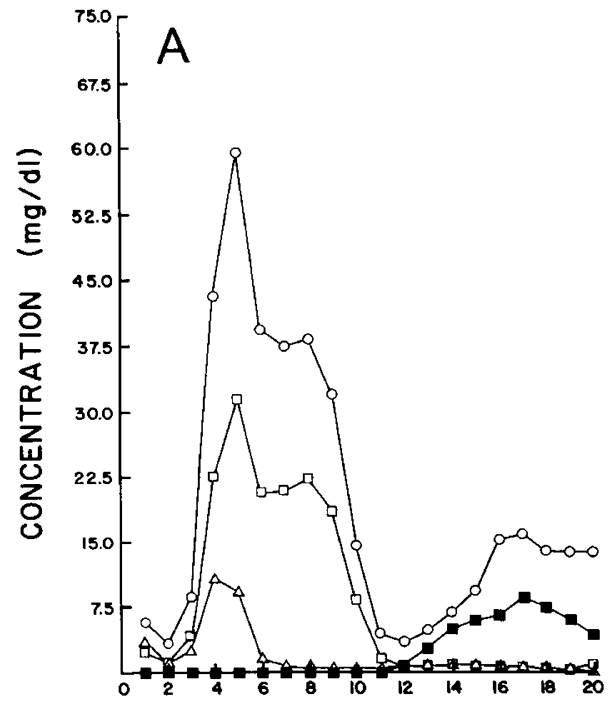

DENSITY GRADIENT FRACTION NO.

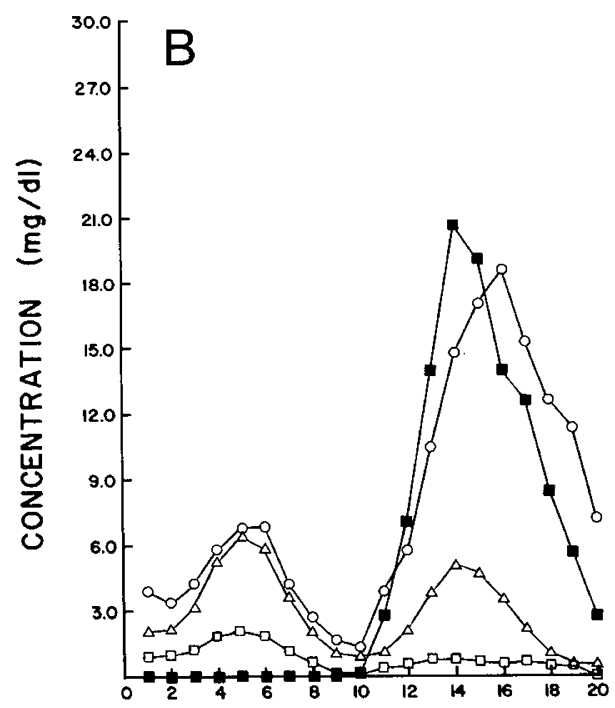

DENSITY GRADIENT FRACTION NO.

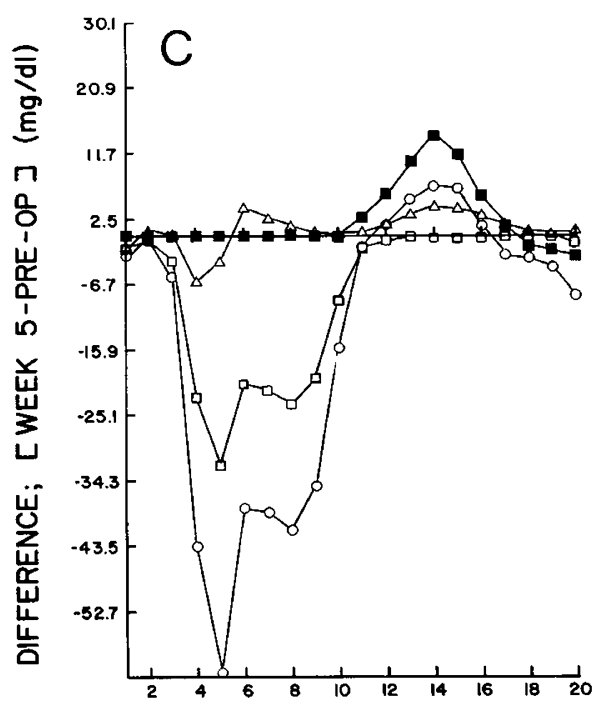

DENSITY GRADIENT FRACTION NO.

Fig. 2. Density gradient profiles of plasma $\mathrm{d}>1.006 \mathrm{~g} / \mathrm{ml}$ lipoproteins from patient B. (Otherwise constructed the same as Figure 1.) 

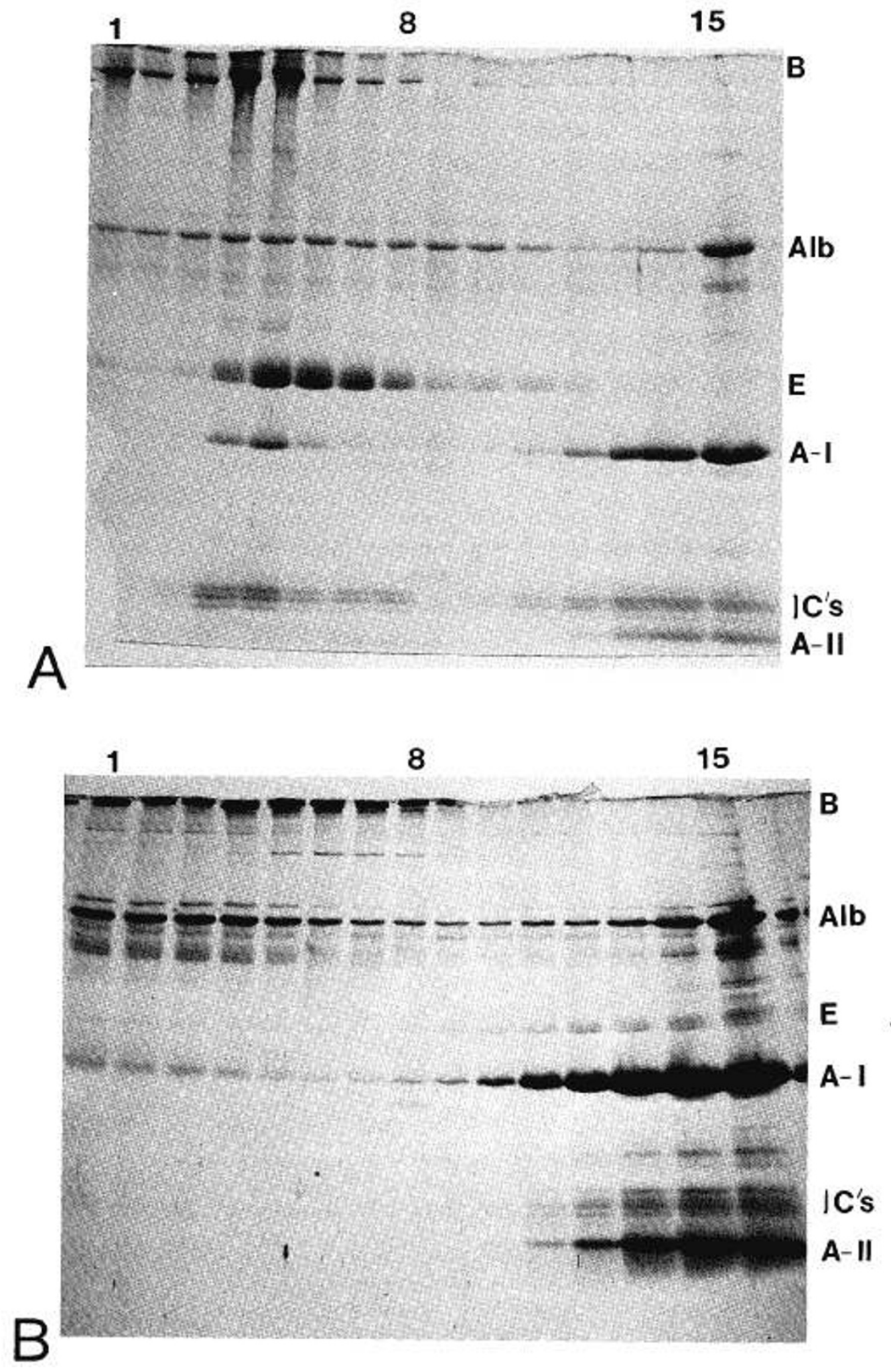

Fig. 3. SDS-PAGE gels showing the apoprotein composition of density gradient fractions of plasma $\mathrm{d}>1.006 \mathrm{~g} / \mathrm{ml}$ lipoproteins from patient $\mathrm{B}$ : $A$, preoperative; $B, 5 \mathrm{wk}$ postoperative. Gradient fraction numbers are listed at the top of the gels and the apoprotein bands are identified at the right of the gel. ( $B$, apo $\mathrm{B}$; alb, albumin; $E$, apo $\mathrm{E} ; A-I$, apo A-I; $C$ 's, apo C peptides; $A-I I$, apo A-II.)

and $\mathrm{Lp}-\mathrm{X}$, and increases of apo A-I, PL, and EC in the HDL density region, predominantly in the "heavy" HDL subspecies (fractions 14-17).

The apoprotein composition of density gradient fractions 115 of the $5 \mathrm{wk}$ postoperative samples differed sharply from preoperative values (Fig. 3). Patient B was normal, apo B being the only protein in the LDL region and apo A-I, A-II, C, and E in fractions 9-15 (Fig. 3B). Patient A's apolipoprotein pattern was similar to patient $B$ at 5 wk; however, some apo E remained in fractions 6-9 (data not shown).

Patient A demonstrated near normal morphology of negatively stained samples of LDL, Lp-X and heavier LDL, and HDL, but 

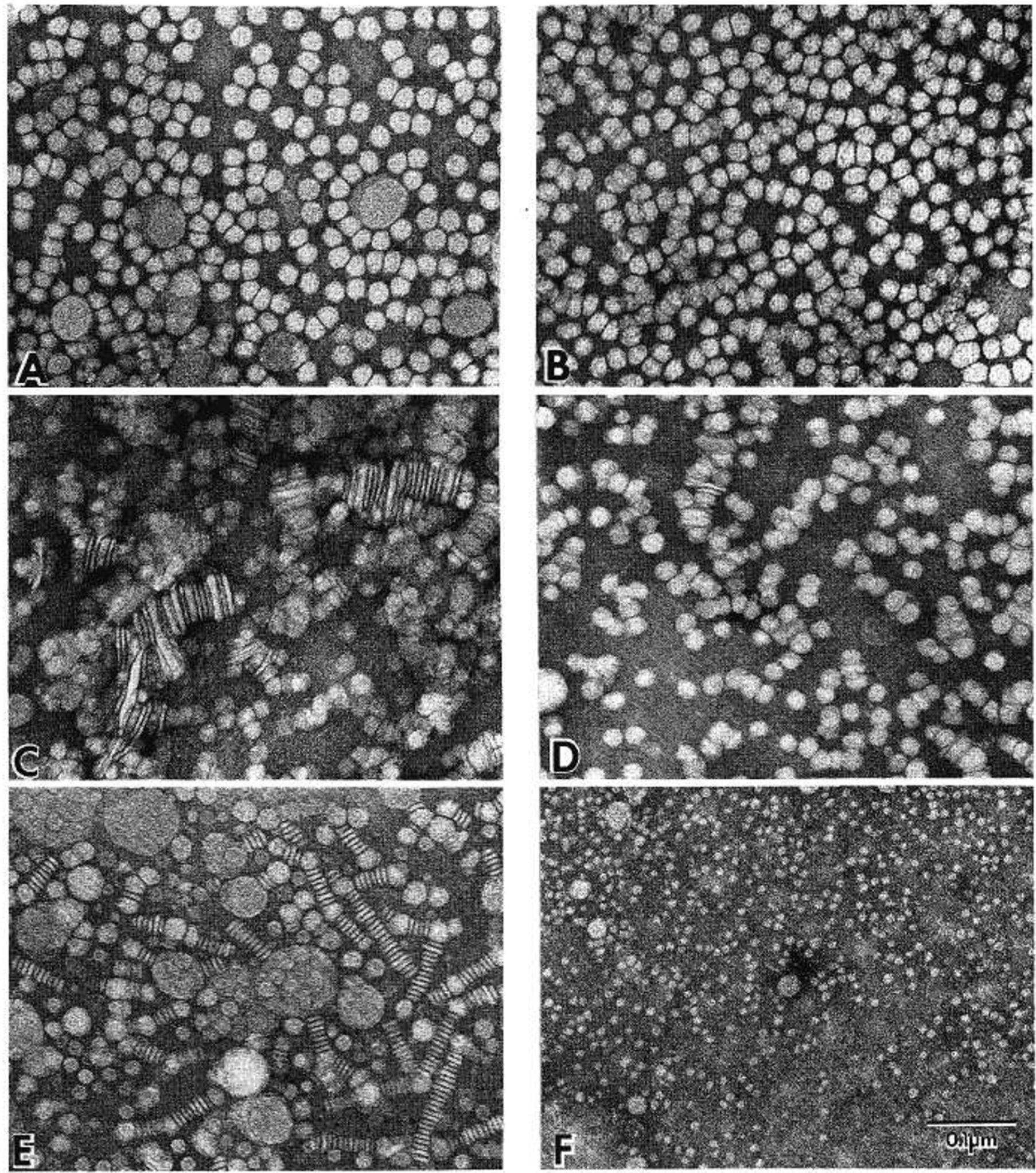

Fig. 4. Electron micrographs of negatively stained $\mathrm{d}>1.006 \mathrm{~g} / \mathrm{ml}$ density gradient lipoproteins from patient A. On the left are preoperative samples; $A, B$ and $C$ are fractions 5,7 , and 13 , respectively. On the right are the corresponding postoperative samples.

some stacked discs were still evident in the Lp-X region (Fig. 4, $D-F)$. Patient B had completely normal lipoprotein morphology (data not shown).

\section{DISCUSSION}

Lipoprotein abnormalities which occur in adult patients during extrahepatic biliary obstruction and their recovery after surgical relief were the subject of a recent report from this laboratory (32). In the only similarly studied case in childhood, Cohlan and Kayden (5) studied a 22 -month-old infant with reversible hyperlipidemia due to choledochal cyst. Over the first 4 days after surgery, the plasma cholesterol level fell from a preoperative concentration of 1860 to $720 \mathrm{mg} / \mathrm{dl}$, and then to normal by 3 months. Electrophoretic lipoprotein analysis showed an elevation in the $\beta$ lipoprotein (LDL) fraction with a large percentage 
contributed by an unusual $\beta$ lipoprotein with a flotation rate of $\mathrm{S}_{\mathrm{f}} 11$. Although not appreciated at that time, this unusual lipoprotein was probably Lp-X. They also reported that no $\alpha$ lipoprotein (HDL) was detected in the preoperative sample. In the postoperative samples, the $\beta$ lipoprotein levels fell and on the 11 th postoperative day, $\alpha$ lipoprotein was detectable for the first time.

The methods used in the present study have enabled us to characterize the alterations in lipids, apoproteins, and particle morphology in the $\mathrm{d}>1.006 \mathrm{~g} / \mathrm{ml}$ plasma lipoproteins. The density gradient profiles in the preoperative samples of our pediatric patients are strikingly similar to those abnormalities found in adult patients with obstructive cholestasis. UC is the predominant form of $\mathrm{CH}$ throughout the gradient with a maximum in the LDL region. Most of the PL is found in fractions $1-13$. There is very little $\mathrm{CH}$ in the "heavy" $\mathrm{HDL}$ region of the gradient (fractions 14-20). The small amount of apo A-I detected in the gradient is found only in the "heavy" HDL and plasma protein pool region.

$\mathrm{Lp}-\mathrm{X}$ is an abnormal particle usually seen in patients with severe cholestasis. Efforts have been made to use Lp-X as a screening test to differentiate neonatal hepatitis from extraheptic biliary atresia $(12,20)$, but overlap has prevented it from gaining acceptance. Recently, observing the change in Lp-X after cholestyramine treatment has been advanced as a refinement which increases the discriminant value (19). The LDL region of density gradients from preoperative samples from our patients demonstrated albumin in fractions 7 and 8 coincident with UC and PL concentration in a 1:1 molar ratio and morphological alterations indicating the presence of $\mathrm{Lp}-\mathrm{X}$. Similar changes have been observed in adult patients with cholestasis (10).

After surgical correction of the extrahepatic biliary obstruction in these patients, the lipoprotein abnormalities in the $\mathrm{d}>1.006$ $\mathrm{g} / \mathrm{ml}$ plasma fraction promptly reversed. PL concentrations decreased steadily throughout the period of follow-up. EC increased rapidly, and UC fell concomitantly. Apo A-I concentration increased in the HDL region. As EC and apo A-I concentrations increased, the morphology of the HDL reverted to normal. As recovery proceeded, apolipoproteins other than apo B disappeared from the LDL region, and LDL morphology became normal. The maxima observed in the PL and UC concentrations in fractions 7 and 8 of the density gradient of preoperative samples disappeared as did the morphologically abnormal stacked discs, indicating disappearance of LP-X. Albumin and apo E disappeared in fractions 4-12. The pattern of recovery in these pediatric patients is remarkably similar to that observed in adults after correction of extrahepatic biliary obstruction (32). Minor differences between our two patients probably relate to the more severe liver disease suffered by patient $\mathrm{A}$ which may have affected the early recovery of HDL apo A-I. These children, like adults with obstruction, tend to have a preferential recovery of the "heavier" HDL species after surgery in contrast to the recovery of the "light" HDL seen after alcoholic hepatitis (33).

Several pathophysiological aberrations resulting from extrahepatic obstruction probably contributed to the abnormal lipoproteins seen in our patients (23). With obstruction the regurgitation of biliary lipid appears to be the primary event altering plasma lipoproteins. This causes plasma $\mathrm{CH}$ to rise by ill-defined mechanisms; synthesis may be increased (6). Lp-X also results from retention of biliary lipid (16). These abnormalities were seen in both of our patients, and both promptly recovered after surgery. Reappearance of $\mathrm{Lp}-\mathrm{X}$ in plasma of patients after hepatoportoenterostomy for biliary atresia has been interpreted as an indicator of surgical failure (20). Similarly, if Lp-X does not promptly disappear or if it reappears from patients after surgical correction of choledochal cyst, it should cause the adequacy of the drainage procedure to be questioned.

Hepatocellular injury and feathery degeneration which result from prolonged severe obstruction cause other mechanisms to come into play. A deficiency of LCAT, the enzyme which catalyzes the formation of CE from UC, probably plays a central role in the formation of apo $\mathrm{E}$ enriched, apo A-I depleted discoidal HDL particles (23-25). Such particles have been observed in perfusates of in vitro rat liver preparations exposed to an LCAT inhibitor and in humans with alcoholic hepatitis and familial LCAT deficiency $(1,11,17,21,29)$. Unfortunately, we did not measure LCAT activity, but LCAT has been shown to be low in adults with biliary obstruction and low plasma EC (1, 21, 29). Apo A-I is a cofactor for LCAT activity, and the low apo A-I observed in our patients could accentuate any LCAT deficiency (9). The interpretation of the HDL data from our patients is far from clear. Patient A had far advanced cirrhosis and lower apo A-I than patient B, but her EC was higher when expressed as an absolute concentration or as a fraction of $\mathrm{CH}$. After surgery, patient B's abnormalities corrected promptly while patient A improved more slowly. After 5 wk patient A's apo AI was normal, but EC was unchanged in concentration and subnormal as a fraction of $\mathrm{CH}$ (64 versus $70 \%$ for patient $\mathrm{B}$ ). We have interpreted this as reflecting the severity of her liver injury. These inconsistencies are difficult to explain and probably indicate other factors are operative. Nevertheless, failure of the HDL abnormalities to correct after surgery probably indicates extensive hepatocellular injury has occurred.

This is the first detailed study of the lipid, apoprotein, and morphological changes of plasma $\mathrm{d}>1.006 \mathrm{~g} / \mathrm{ml}$ lipoproteins in young children recovering from extrahepatic biliary obstruction. These abnormalities appear to correct promptly after surgical repair if little hepatic injury has occurred. The recovery patterns were very similar to those of adults. These data suggest that plasma lipoproteins could be important prognostic indicators of recovery in infants with extrahepatic biliary obstruction.

Acknowledgments. The authors gratefully acknowledge Sharon Frase, Lois Kuiken, and Polina Kogan for excellent technical assistance, and Becky Potter for careful preparation of this manuscript.

\section{REFERENCES}

1. Agorastos J, Fox C, Harry DS, et al 1978 Lecithin-cholesterol acyltransferase and the lipoprotein abnormalities of obstructive jaundice. Clin Sci Mol Med 54:369-379

2. Alonso-Lej F, Rever WB, Pessagno DJ 1959 Congenital choledochal cyst, with a report of two, and an analysis of 94 cases. Int Abstr Surg 108:1-30

3. Arnesjo B, Danielsson B, Ekman R, et al 1977 Characterization of high density lipoproteins in human cholestasis. Scand J Clin Lab Invest 37:587-597

4. Blomhoff JP 1973 Serum cholesterol determined by gas-liquid chromatography. Clin Chim Acta 43:257-265

5. Cohlan SQ, and Kayden JK 1962 Reversible hyperlipidemia and skin xanthomas in obstructive biliary disease due to choledochal cyst. Am J Med 32:989994

6. Cooper AD, Ockner RK 1974 Studies of hepatic cholesterol synthesis in experimental acute biliary obstruction. Gastroenterology 66:586-595

7. Curry MD, Alaupovic $P$, and Suenram $C H 1976$ Determination of apoprotein $\mathrm{A}$ and its constitutive A-I and A-II polypeptides by separate electroimmunoassays. Clin Chem 22:315-322

8. Curry MD, Gustafson A, Alaupovic P, et al 1978 Electroimmunoassay, radioimmunoassay, and radial immunodiffusion assay evaluated for quantitation of human apolipoprotein B. Clin Chem 24:280-286

9. Fielding CJ, Shore VG, and Fielding PE 1972 A protein cofactor of lecithin:cholesterol acyltransferase. Biochem Biophys Res Commun 46:14931498

10. Hamilton RL, Havel RJ, Kane JP, et al 1971 Cholestasis: lamellar structure of abnormal human serum lipoproteins. Science 172:4754-4758

11. Hamilton RL, Williams MC, Fielding CJ, et al 1976 Discoidal bilayer structure of nascent high density lipoproteins from perfused rat liver. J Clin Invest 58:667-680

12. Johnson JD 1975 Neonatal nonhemolytic jaundice. N Engl J Med, 292:194197

13. Laemmli VK 1970 Cleavage of structural proteins during the assembly of the head of bacteriophage T4. Nature 227:680-685

14. Laurell CB 1966 Quantitative estimation of proteins by electrophoresis in agarose gel containing antibodies. Anal Biochem 15:45-52

15. Markwell MK, Haas SM, Briever LL, et al 1978 A modification of the Lowry procedure to simplify protein determination in membrane and lipoprotein samples. Anal Biochem 87:206-210

16. Monzato E, Fellin R, Baggio G, et al 1976 Formation of lipoprotein-X. Its relationship to bile compounds. J Clin Invest 57:1248-1260 
17. Norum KR, Gjone E 1967 Familial plasma lecithin:cholesterol acyltransferase deficiency. Biochemical study of a new inborn error of metabolism. Scand Clin Lab Invest 20:231-243

18. Orenstein SR, Whitington PF 1983 Choledochal cyst resulting in congenital cirrhosis. Am J Dis Child 136:1025-1026

19. Poley JR, Alaupovic P, Knight-Gibson C, and Caplan DB 1983 The quantitative determination of serum lipoprotein- $X$ and apolipoproteins in infants with cholestatic liver and biliary tract disease. In: Daum $F$ (ed) Extrahepatic Biliary Atresia. Marcel Dekker, New York, pp 33-41

20. Poley JR, Alaupovic P, McConathy WJ, et al 1973 Diagnosis of extrahepatic biliary obstruction in infants by immunochemical detection of LP.X and modified ${ }^{131}$ I-rose bengal excretion test. J Lab Clin Med 81:325-341

21. Ritland S, Blomhoff JP, and Gjone E 1973 Lecithin:cholesterol acyltransferase and lipoprotein-X in liver disease. Clin Chim Acta 49:251-259

22. Rouser G, Fleischer S, and Yamamoto AP 1969 Two dimensional thin layer chromatographic separation of polar lipids and determination of phospholipids by phosphorus analysis of spots. Lipids 5:494-496

23. Sabesin SM 1982 Cholestatic lipoproteins-their pathogenesis and significance. Gastroenterology 83:704-709

24. Sabesin SM, Bertram PD, and Freeman MR 1980 Lipoprotein metabolism in liver disease. Adv Intern Med 25:117-146

25. Sabesin SM, Ragland JB, and Freeman MR 1979 Lipoprotein disturbances in liver disease. Popper H, Schaffner F (eds) Progress in Liver Diseases. Grune and Stratton, New York, pp 243-262
26. Sanar J, Skrede S, and Blomhoff JP 1978 Hepatic lipase and lipoprotein lipase in postheparin plasma in liver disease. Relations to plasma proteins. Clin Chim Acta 84:213-223

27. Seidel D, Alaupovic P, and Furman RH 1969 A lipoprotein characterizing obstructive jaundice. I. Method for quantitative separation and identification of lipoproteins in jaundiced subjects. J Clin Invest 48:1211-1223

28. Seidel D, Alaupovic P, Furman RH, et al 1970 A lipoprotein characterizing obstructive jaundice. II. Isolation and characterization of protein moieties of low-density lipoproteins. J Clin Invest 49:2396-2407

29. Turner KB, McCormack GH Jr, Richards A 1953 The cholesterol esterifying enzyme of human serum. I. In liver disease. J Clin Invest 32:80 I-806

30. Weber K, and Osborn M 1969 The reliability of molecular weight determination by dodecyl sulfate-polyacrylamide gel electrophoresis. J Biol Chem 244:4406

31. Weidman SW, Ragland JB, Fisher JN, et al 1982 Effects of insulin on plasma lipoproteins in diabetic ketoacidosis: evidence for a change in high density lipoprotein composition during treatment. J Lipid Res 23:171-182

32. Weidman SW, Ragland JB, Jones WE, et al 1984 Plasma lipoprotein composition in cholestasis: accumulation of abnormal lipoproteins and changes during partial recovery. Hepatology (in press)

33. Weidman SW, Ragland JB, and Sabesin SM 1982 Plasma lipoprotein composition in alcoholic hepatitis: accumulation of apolipoprotein E-rich high density lipoproteins and preferential reappearance of "light"-HDL during partial recovery. J Lipid Res 23:556-569

\title{
Heat- and Alcohol-Induced Neural Tube Defects: Interactions with Folate in a Golden Hamster Model
}

\author{
JOHN M. GRAHAM, JR. AND VERGIL H. FERM \\ Dysmorphology Unit, Department of Maternal and Child Health [J.M.G.], and Department of Anatomy, \\ Dartmouth Medical School IV.H.F.J, Hanover, New Hampshire 03756
}

\begin{abstract}
Maternal hyperthermia or ethanol each can induce fetal neural tube defects (NTD) following exposures on the 8th day of gestation in golden hamsters. To explore the relationship between NTD and varying doses of either heat or ethanol, timed pregnant golden hamsters were exposed to various doses of either $25 \%$ ethanol, or heat in an incubator at $39.5^{\circ} \mathrm{C}$ on the morning of the 8th day of gestation. Two doses of $0.015 \mathrm{ml} / \mathrm{g}$ body weight of $25 \%$ ethanol $4 \mathrm{~h}$ apart resulted in a $44 \%$ incidence of NTD when fetuses were examined on day 13 . Single doses of $25 \%$ ethanol (either 0.015 or $0.0075 \mathrm{ml} / \mathrm{g}$ ) resulted in very low incidences of NTD that were not significantly different from zero. A 50-min exposure to heat resulted in a $35 \%$ incidence of NTD. A shorter exposure (44 $\mathrm{min}$ ) resulted in a $23 \%$ incidence, and a longer exposure $(56 \mathrm{~min})$ resulted in a $68 \%$ incidence of NTD. A $0.0075 \mathrm{ml} / \mathrm{g}$ dose of $25 \%$ ethanol, followed by these same durations of heat, resulted in incidences of NTD that were not significantly different from heat alone. In order to determine what effect folate supplementation might have on ethanol- or heat-induced
\end{abstract}

Received March 12, 1984; accepted October 2, 1984

Address for Reprints John M. Graham, Jr., M.D., ScD., Dysmorphography Unit, Department of Maternal and Child Health, Dartmouth Medical School, Hanover, NH 03756.

Supported by BRSG Grant 2507-RR05392-21 [J.M.G.], Hitchcock Foundation Research Project Grant 51 [J.M.G.], and NIH Grant OH-01434 [V.H.F.].
NTD, osmotic pumps filled with either folate or saline were placed subcutaneously in pregnant hamsters on the 6th day of gestation. Animals were then exposed to ethanol or heat on the morning of day 8 . No significant protection from NTD was evident among fetuses from mothers supplemented with folate despite significant elevations in their red cell folate levels on day 8 of gestation. (Pediatr Res 19: 247-251, 1985)

\section{Abbreviation}

NTD, neural tube defect(s)

Experimental results from several animal species suggest that hyperthermia during the time of neural tube closure may lead to NTD $(7,8,15,26)$. Furthermore, epidemiologic studies suggest the human embryo is not immune to such effects $(2,10,14,21)$. Such studies suggest that as many as $10 \%$ of live births and $14 \%$ of human abortuses with NTD may have been exposed to hyperthermia during early gestation (25). Other studies have documented frequent occurrences of anencepahly following epidemics of febrile illnesses such as influenza $(5,6,13)$. Similarly, experimental studies suggest that exposure to high doses of 